\title{
Analysis of sentinel lymph node biopsy results in colon cancer in regard of the anthropometric features of the population and body composition assessment formulas
}

\author{
Piotr Nowaczyk • Dawid Murawa • Karol Połom • \\ Magdalena Waszyk-Nowaczyk • Arkadiusz Spychała • \\ Michał Michalak • Pawel Murawa
}

Received: 3 December 2011 / Accepted: 16 February 2012 / Published online: 14 March 2012

(C) The Author(s) 2012. This article is published with open access at Springerlink.com

\begin{abstract}
Purpose The aim of the study was to assess sentinel lymph node biopsy (SLNB) results in colon cancer (CC) regarding basic anthropometric features of the studied population and their derivatives calculated using mathematical formulas. Methods One hundred three SLNBs in CC have been analysed. Various indicators were calculated for every patient using mathematical formulas: BMI, Roher's index, lean body weight, body fat percentage and body weight/ideal body weight for a given height ratios using the following formulas: Broca's, Broca's ideal weight, Broca-Brugsch, Lorenz's, Potton's, Devine's, Robinson's, Miller's and Hamwi. The
\end{abstract}

P. Nowaczyk $(\bowtie) \cdot$ D. Murawa $\cdot$ K. Połom $\cdot$ A. Spychała P. Murawa

1st Clinic of Surgical Oncology and General Surgery,

Wielkopolska Cancer Centre,

ul. Garbary 15 ,

61-866 Poznań, Poland

e-mail: piotr_nowaczyk@o2.pl

M. Waszyk-Nowaczyk

Pharmacy Practice Division, Chair and Department

of Pharmaceutical Technology,

Poznan University of Medical Sciences,

ul. Bukowska 70,

60-812 Poznań, Poland

M. Michalak

Department of Computer Science and Statistics,

Poznan University of Medical Sciences,

ul. Dąbrowskiego 79,

60-529 Poznań, Poland

P. Murawa

Department of Oncological Pathomorphology,

Wielkopolska Cancer Centre,

ul. Garbary 15 ,

61-866 Poznań, Poland results were compared with accuracy, sensitivity and false negative results percentage by means of ROC curves and the test for structure indicators (for determined cut-off points). Results No statistically significant relationship between the results and patients' sex or age were found. ROC curve analysis did not reveal statistically significant relationships between the obtained results and indicators calculated on the basis of growth and weigh (all $p>0.05$ ). The analyses of sensitivity and accuracy with determined cut-off point, in spite of differences amounting to $19 \%$ (analysis of lean body weight/weight ratio), showed no statistical significance for any of the relationships (all $p>0.05$ ).

Conclusions No indicator with high diagnostic and prognostic value has been found. The problem of qualifying patients for SLNB in CC in regard of the anthropometric features of the population and body composition assessment formulas remains open and requires further analysis on larger populations.

Keywords Sentinel node biopsy - Colon cancer . Anthropometric features $\cdot$ BMI $\cdot$ Body composition

\section{Introduction}

The most important prognostic factor in the colorectal cancer (CRC) is the local lymphoid system's status. Lymph node (LN) metastasis lowers 5-year survival rate from 70 $90 \%$ to $40-60 \%$ [1-6]. In case of colon cancer (CC) regional lymphoid system involvement decides patient's eligibility for adjuvant therapy, chemotherapy significantly improves survival rate [2,6-11]. Up to $30 \%$ of the after surgery pN0 patients will die within 5 years due to local recurrence or remote metastasis [3,6-13]. As a result, it 
seems appropriate to establish a "high risk" stage II group that potentially may benefit from adjuvant therapy $[1,3,7$, $8,14,15]$. Presently, the improvement of diagnosing the LNs seems essential. The sentinel lymph node biopsy (SLNB) in CC enables examination of the first nodal station of the lymphatic drainage from the tumour. Precise examination of these LNs using serial tissue slicing, immunohistochemical staining (IHC) and reverse transcription polymerase chain reaction may potentially upstage lymphoid system status compared to the results achieved using haematoxylin and eosin staining (H\&E) [3-13, 16, 17]. It needs to be stressed that an en block resection of the tumour with a margin of healthy tissue and mesocolon remains the standard treatment. Recent suggestions to implement SLNB as a mesocolon-sparing treatment during laparoscopic procedures constitute a separate issue [5, 11, 17-19].

Presently, with the ongoing dispute whether to perform SLNB in CC, there's a need to determine the group of patients who will benefit from it maximally. Qualifying patients means, on one hand, fulfilling certain eligibility criteria and, on the other hand, the issue of stating measurable indicators whether the procedure is legitimate for a given group of patients. Available literature doesn't provide a consensus on qualifying patients regarding basic anthropometric features, such as height, weight and possible derivatives such as Body Mass Index (BMI). Data from papers on SLNB in diseases where it's a standard procedure (breast cancer, melanoma) suggest there's a relation between BMI and efficacy and sensitivity of the procedure [20-25]. Analogically, it's claimed that intra-abdominal obesity may cause difficulties in identifying dyed LNs in the mesocolon. Consequently, it may induce mistakes during the procedure, lowering detection rates or increasing the number of false negative results. This problem affects the most important trend, i.e. SLNB as an extra diagnostic tool for patients with negative H\&E staining results of LNs [19, 26, 27]. It's also influencing the perspectives of using lymph node mapping (LNM) as a mesocolon-sparing treatment.

The aim of this work is to analyse the results of SLNB in $\mathrm{CC}$ in regard of basic anthropometric features of the studied population and their derivatives calculated with mathematical formulas. These features may potentially allow assessment of the intra-abdominal obesity and the risk of excessive mesocolon adipose tissue.

\section{Materials and methods}

One hundred three SLNBs in CC have been performed in the 1st Clinic of Surgical Oncology and General Surgery, Wielkopolska Cancer Centre during the period of time from May, 2005 till November, 2010. The studied group consisted of 48 men and 55 women, median age 65 (IQR 56-
70). Division of patients according to cancer stage without taking into consideration the IHC examination of sentinel lymph nodes (SLNs) (according to AJCC Cancer Staging Manual, Seventh Edition 2010) is presented in Table 1.

The criteria of eligibility for the study were: histopathologically confirmed and resectable colon cancer, patient's age over 18 years old, good overall physical status (ASA I-III), no prior colon or mesocolon surgeries (including appendectomy in case of tumours of the right side of the colon). Patients with intraoperatively assessed suspicious LNs, locally advanced tumours, distant metastases, synchronised neoplasms and operated due to emergency indications (intestinal obstruction) were excluded from the study. All the procedures were open surgeries. Each SNLB was performed by a surgical team including a surgeon who has completed at least ten procedures of this type.

After opening the abdomen in the large intestine, fragment that was to be removed was delicately mobilised in each case. Subserosally, 2-4 $\mathrm{ml}$ of Patent Blue dye was administered by four injections. Then pigmentation of lymph vessels and nodes was observed, and sentinel nodes were defined as the first nodes pigmented after 5-10 $\mathrm{min}$ from dye application. SLNs were marked with a suture to be subsequently sent for analysis (during or after the procedure) while a standard en block resection of the tumour with a margin of healthy tissue and mesocolon lymphoid system was completed.

Specimen collected during the operation was fixated in a standard way, embedded in paraffin and stained with H\&E. If no macrometastases were present, the multisectioning was used for processing the SLNs. The material was cut into sections of the thickness of $250 \mu \mathrm{m}$. On each of the obtained

Table 1 Division of material with respect to cancer staging according to the TNM, Classification of Malignant Tumours by Dukes and Dukes, modified by Astler and Coller (in accordance with AJCC Cancer Staging Manual, Seventh Edition 2010)

\begin{tabular}{lllllll}
\hline Stage & T & N & M & Dukes & MAC & Patients (\%) \\
\hline 0 & Tis & N0 & M0 & - & - & $2(1.9 \%)$ \\
I & T1 & N0 & M0 & A & A & $6(5.8 \%)$ \\
& T2 & N0 & M0 & A & B1 & $15(14.6 \%)$ \\
IIA & T3 & N0 & M0 & B & B2 & $50(48.5 \%)$ \\
IIIA & T2 & N1a & M0 & C & C1 & $1(1.0 \%)$ \\
& T2 & N1b & M0 & C & C1 & $1(1.0 \%)$ \\
IIIB & T2 & N2a & M0 & C & C1 & $2(1.9 \%)$ \\
& T2 & N2b & M0 & C & C1 & $1(1.0 \%)$ \\
& T3 & N1a & M0 & C & C2 & $9(8.7 \%)$ \\
& T3 & N1b & M0 & C & C2 & $7(6.8 \%)$ \\
& T3 & N2a & M0 & C & C2 & $5(4.9 \%)$ \\
IIIC & T3 & N2b & M0 & C & C2 & $3(2.9 \%)$ \\
& T4a & N2a & M0 & C & C2 & $1(1.0 \%)$ \\
\hline
\end{tabular}

$T$ tumour, $N$ nodes, $M$ metastasis, Dukes Dukes staging system, $M A C$ Dukes, modified by Astler and Coller, staging system 


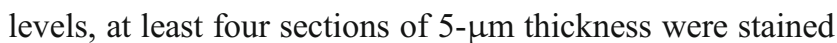
immunohistochemically (CKMNF116 (Code: M 0821), CKAE1/AE3 (Code: M 3515) monoclonal antibodies, DAKO company, CAM 5,2 (No. 345779) monoclonal antibodies, Becton Dickinson).

SLN was qualified as positive if there was a positive result in H\&E staining and if there were micrometastases (foci of cancer cells $0.2-2 \mathrm{~mm}$ in diameter) in IHC. LNs containing isolated cancer cells (foci of cells $<0.2 \mathrm{~mm}$ in diameter) or single cells positive in cytokeratin stain were classified as negative.

To assess efficacy and quality of the procedure, levels of detection, sensitivity and accuracy were calculated. Upstaging, false positive results and the negative predictive value were also calculated. Subsequently, the results were compared to age and sex of the patients. BMI was calculated for every patient using a formula: BMI $=\frac{\text { body weight in kg }}{(\text { height in } \mathrm{m})^{2}}$; Roher's index using a formula: Roher's index $=\frac{\text { body weight in kg }}{(\text { height in } \mathrm{m})^{3}}$; lean body weight using formulas: Lean Body Weight for men $=(1.2 \times$ body weight in $\mathrm{kg})$ $-128\left(\frac{(\text { body weight in } \mathrm{kg})^{2}}{(100 \times \text { height in } \mathrm{m})^{2}}\right), \quad$ Lean Body Weight for women $=$ $(1.07 \times$ body weight in $\mathrm{kg})-148\left(\frac{(\text { body weight in } \mathrm{kg})^{2}}{(100 \times \text { height in } \mathrm{m})^{2}}\right) ;$ Body Fat Percentage using a formula: Body Fat $\%=1.2 \times \mathrm{BMI}+$ $0.23 \times$ age in years $-10.8 \times(\mathrm{sex} ; \mathrm{M}=1, \mathrm{~F}=0)-5.4$. Body weight for a given height was calculated using Broca's index: proper weight $=$ height in $\mathrm{cm}-100$; Broca's formula for ideal weight: ideal weight $\mathrm{F}=0.85 \times$ (height in $\mathrm{cm}-100)$, ideal weight $\mathrm{M}=$ $0.9 \times$ (height in $\mathrm{cm}-100)$; Broca-Brugsch formula: ideal weight $=$ height in $\mathrm{cm}-100$ (for height $155-164 \mathrm{~cm}$ ) or ideal weight $=$ height in $\mathrm{cm}-105$ (for height $165-175 \mathrm{~cm}$ ) or ideal weight $=$ height in $\mathrm{cm}-110$ (for height $176-190 \mathrm{~cm}$ ); Lorentz formula for height $\geq 150 \mathrm{~cm}$ : proper weight=height in $\mathrm{cm}-100-0.25 \times($ height in $\mathrm{cm}-150)$; Potton's formula: proper weight $\mathrm{M}=$ height in $\mathrm{cm}-100-\left(\frac{\text { height in } \mathrm{cm}-100}{20}\right)$, proper weight $\mathrm{F}=$ height in $\mathrm{cm}-100-\left(\frac{\text { height in } \mathrm{cm}-100}{10}\right)$. We also calculated body weight using formulas known in drugs dosage calculations: Devine's formula: ideal weight $\mathrm{M}=50+$ $2.3 \mathrm{~kg}$ for every inch over $5 \mathrm{ft}$, ideal weight $\mathrm{F}=45.5+2.3 \mathrm{~kg}$ for every inch over $5 \mathrm{ft}$; Robinson's formula: ideal weight $\mathrm{M}=52+$ $1.9 \mathrm{~kg}$ for every inch over $5 \mathrm{ft}$, ideal weight for women $=49+$ $1.7 \mathrm{~kg}$ for every inch over $5 \mathrm{ft}$; Miller's formula: ideal weight $\mathrm{M}=56.2+1.41 \mathrm{~kg}$ for every inch over $5 \mathrm{ft}$, ideal weight $\mathrm{F}=$ $53.1+1.36 \mathrm{~kg}$ for every inch over $5 \mathrm{ft}$; Hamwi formula: ideal weight $\mathrm{M}=48+2.7 \mathrm{~kg}$ for every inch over $5 \mathrm{ft}$, ideal weight $\mathrm{F}=$ $45.5+2.2 \mathrm{~kg}$ for every inch over $5 \mathrm{ft}$. The result from every weight formula was matched to patient's current weight: current weight/ideal weight according to a given formula.

Results for each sex were analysed using chi-square test, for every variable depending on sex, age, mass and height, ROC graphs were plotted to find cut-off points for sensitivity, accuracy, and false negative results percentage in SLNB in CC. Additionally, cut-off points were determined for particular calculated parameters: for BMI, 23 and 25; for lean body weight, 0.72 ; for body fat percentage, $28 \%$; for all the ratios current weight/ideal weight for a given height, 1. The obtained results were analysed in terms of method sensitivity and accuracy, each single time comparing two groups on the both sides of a cut-off point with the use of the test for structure indicators.

The study has been approved by the Bioethics Commission of Poznan University of Medical Sciences.

\section{Results}

In an average specimen, 14.3 LNs were analysed (median 13 , IQR 9.75-18). In $66 \%$ (68) of patients 12 or more LNs were analysed. No complications during SLNB procedure were observed and at least one SLN (median 3, IQR 2-4) was identified in 102 out of 103 patients (99\%). After H\&E and IHC staining, the SLN was confirmed as the only place of metastasis in 13/102 patients $(12.7 \%)$. Accuracy of SLN in predicting the status of the local lymphatic system was $94.1 \%(96 / 102)$. Sensitivity of the method in predicting the status of the local lymphatic system was $84.2 \%(32 / 38)$. The index of false negative results was $15.8 \%(6 / 38)$. In three out of these six patients, aberrant lymphatic drainage (ALD) was observed after administering dye; mesenteric root LN were marked. ALD percentage was $2.9 \%(3 / 102)$. Negative predictive value was $91.4 \%$ (64/70). In seven patients with negative SLN after H\&E staining and its positive result in IHC stain, no tumour deposits were found in the remaining specimen, so the upstaging due to $\mathrm{IHC}$ stain was $9.9 \%(7 / 71)$.

Median height in the population was $1.68 \mathrm{~m}$ (IQR 1.60 $1,72 \mathrm{~m}$ ). Median body weight was $72 \mathrm{~kg}$ (IQR 61.5-81.25). Median BMI was $25.64 \mathrm{~kg} / \mathrm{m}^{2}$ (IQR 22.63-28.33 kg/m²). There was no statistically significant difference in the results regarding sex and age of the patients. In the plotted ROC graphs, there was no significant relation for all of the indicators calculated based on body weight and height. In the studied material, height/weight ratio (area under curve$\mathrm{AUC}=0.50, p=0.4771)$, BMI $(\mathrm{AUC}=0.53, p=0.3223)$, Roher's index (AUC $=0.54, p=0.2340)$, lean body weight/ weight ratio ( $\mathrm{AUC}=0.42, p=0.9258)$, body fat percentage (AUC $=0.57, p=0.1171)$ and the ideal weight calculated using Broca's (AUC $=0.54, p=0.2790)$, Broca's ideal weight $(\mathrm{AUC}=0.54, p=0.2441)$, Broca-Brugsch $(\mathrm{AUC}=0.51, p=$ $0.4123)$, Lorenz's (AUC $=0.48, p=0.6153)$, Potton's (AUC $=0.54, p=0.2494)$, Devine's $(\mathrm{AUC}=0.55, p=$ 0.2216), Robinson's ( $\mathrm{AUC}=0.55, p=0.2088)$, Miller's $(\mathrm{AUC}=0.53, p=0.3112)$ and Hamwi $(\mathrm{AUC}=0,56, p=$ 0.1651 ) formulas were all insignificant. 
The results of sensitivity and accuracy obtained in particular groups for the determined cut-off points are presented in Tables 2 and 3. In spite of differences in the sensitivity and accuracy of the method, reaching $19 \%$ and obtained in the calculations for the particular groups, statistical significance was not found for any of the parameters.

\section{Discussion and conclusions}

The influence of anthropometric factors on SLNB is treated marginally in literature. The vast majority of available data concerns breast cancer where mostly isotope and dye double technique is used. Radiocolloid is used very rarely in SLNB in CC (it migrates faster in colon LVs than in breast or melanoma, thus increasing the probability of marking more hot sentinel nodes; also, identification is harder due to closeness of the primary tumour and the node and the radiation overlap) $[13,26,28-30]$. Nevertheless, in view of general study ideas and lack of reports, the problem seems worth mentioning. In a multi-centre British study ALMANAC [20] on SLNB in breast cancer, there was a relation found between BMI and detection rate- the group with $\mathrm{BMI} \leq 30 \mathrm{~kg} / \mathrm{m}^{2} \quad(n=425)$ showed statistically higher detection rate than the group with $\mathrm{BMI}>30 \mathrm{~kg} / \mathrm{m}^{2}(n=113)$ $(98.1 \%$ vs. $87.6 \%, p<0.001)$. The relation was not confirmed for the percentage of false negative results. Another study analysing 748 SLNBs in breast cancer [21] has shown that SLN identification failure rate was $15.9 \%$ for patients with BMI $>27 \mathrm{~kg} / \mathrm{m}^{2}, 8.5 \%$ for patients with BMI of 22.5 $27 \mathrm{~kg} / \mathrm{m}^{2}$ and $7.7 \%$ for patients with $\mathrm{BMI}<22.5 \mathrm{~kg} / \mathrm{m}^{2}$. This study additionally stated that high BMI not only reduces tissue translucency but also that excessive fat may pressurise LV walls interfering with proper drainage. An American study [22] analysing 2,495 SLNBs in breast cancer using isotope-dye technique demonstrated inverse relation between BMI and identification frequency $(r=-0.98$, $p=0.002$ ). This relation was statistically significant in groups under and over 50 years old. An average BMI was compared in groups with positive and negative identification showing statistically significant difference ( 25.9 vs. 29.4, $p<0.001$ ) both in groups under and over 50 years old. A multifactorial analysis stated that age and BMI have the most significant (inversely proportional) influence on LNM efficacy. Similar results were obtained also in some
Table 2 Sensitivity results obtained in particular groups for the determined cut-off points

\begin{tabular}{|c|c|c|c|}
\hline \multirow[t]{4}{*}{ BMI } & $<25$ & $\geq 25$ & $p$ value \\
\hline & $75 \%$ & $91 \%$ & 0.1811 \\
\hline & $<23$ & $\geq 23$ & $p$ value \\
\hline & $80 \%$ & $86 \%$ & 0.6534 \\
\hline \multirow[t]{2}{*}{ Lean body weight/body weight } & $\geq 0.72$ & $<0.72$ & $p$ value \\
\hline & $94 \%$ & $75 \%$ & 0.1107 \\
\hline \multirow[t]{2}{*}{ Body Fat Percentage } & $<28 \%$ & $\geq 28 \%$ & $p$ value \\
\hline & $100 \%$ & $82 \%$ & 0.3542 \\
\hline \multirow[t]{2}{*}{ Weight/Broca weight for a given height } & $<1.00$ & $\geq 1.00$ & $p$ value \\
\hline & $85 \%$ & $84 \%$ & 0.9359 \\
\hline \multirow[t]{2}{*}{ Weight/ideal weight Broca } & $<1.00$ & $\geq 1.00$ & $p$ value \\
\hline & $100 \%$ & $83 \%$ & 0.5244 \\
\hline \multirow[t]{2}{*}{ Weight/ideal weight Broca-Brugsch } & $<1.00$ & $\geq 1.00$ & $p$ value \\
\hline & $80 \%$ & $86 \%$ & 0.6534 \\
\hline \multirow[t]{2}{*}{ Weight/ideal weight Loretz } & $<1.00$ & $\geq 1.00$ & $p$ value \\
\hline & $78 \%$ & $86 \%$ & 0.5864 \\
\hline \multirow[t]{2}{*}{ Weight/ideal weight Potton } & $<1.00$ & $\geq 1.00$ & $p$ value \\
\hline & $86 \%$ & $84 \%$ & 0.8953 \\
\hline \multirow[t]{2}{*}{ Weight/ideal weight Devine } & $<1.00$ & $\geq 1.00$ & $p$ value \\
\hline & $100 \%$ & $82 \%$ & 0.3542 \\
\hline \multirow[t]{2}{*}{ Weight/ideal weight Robinson } & $<1.00$ & $\geq 1.00$ & $p$ value \\
\hline & $80 \%$ & $85 \%$ & 0.7743 \\
\hline \multirow[t]{2}{*}{ Weight/ideal weight Miller } & $<1.00$ & $\geq 1.00$ & $p$ value \\
\hline & $88 \%$ & $83 \%$ & 0.7314 \\
\hline \multirow[t]{2}{*}{ Weight/ideal weight Hamwi } & $<1.00$ & $\geq 1.00$ & $p$ value \\
\hline & $89 \%$ & $83 \%$ & 0.6646 \\
\hline
\end{tabular}


Table 3 Accuracy results obtained in particular groups for the determined cut-off points

\begin{tabular}{|c|c|c|c|}
\hline \multirow[t]{4}{*}{ BMI } & $<25$ & $\geq 25$ & $p$ value \\
\hline & $91 \%$ & $96 \%$ & 0.2987 \\
\hline & $<23$ & $\geq 23$ & $p$ value \\
\hline & $93 \%$ & $95 \%$ & 0.6938 \\
\hline \multirow[t]{2}{*}{ Lean body weight/body weight } & $\geq 0.72$ & $<0.72$ & $p$ value \\
\hline & $98 \%$ & $92 \%$ & 0.1919 \\
\hline \multirow[t]{2}{*}{ Body Fat Percentage } & $<28 \%$ & $\geq 28 \%$ & $p$ value \\
\hline & $100 \%$ & $93 \%$ & 0.2153 \\
\hline \multirow[t]{2}{*}{ Weight/Broca weight for a given height } & $<1.00$ & $\geq 1.00$ & $p$ value \\
\hline & $95 \%$ & $93 \%$ & 0.6812 \\
\hline \multirow[t]{2}{*}{ Weight/ideal weight Broca } & $<1.00$ & $\geq 1.00$ & $p$ value \\
\hline & $100 \%$ & $94 \%$ & 0.476 \\
\hline \multirow[t]{2}{*}{ Weight/ideal weight Broca-Brugsch } & $<1.00$ & $\geq 1.00$ & $p$ value \\
\hline & $92 \%$ & $95 \%$ & 0.571 \\
\hline \multirow[t]{2}{*}{ Weight/ideal weight Loretz } & $<1.00$ & $\geq 1.00$ & $p$ value \\
\hline & $91 \%$ & $95 \%$ & 0.4738 \\
\hline \multirow[t]{2}{*}{ Weight/ideal weight Potton } & $<1.00$ & $\geq 1.00$ & $p$ value \\
\hline & $94 \%$ & $94 \%$ & 1 \\
\hline \multirow[t]{2}{*}{ Weight/ideal weight Devine } & $<1.00$ & $\geq 1.00$ & $p$ value \\
\hline & $100 \%$ & $93 \%$ & 0.3648 \\
\hline \multirow[t]{2}{*}{ Weight/ideal weight Robinson } & $<1.00$ & $\geq 1.00$ & $p$ value \\
\hline & $92 \%$ & $94 \%$ & 0.7809 \\
\hline \multirow[t]{2}{*}{ Weight/ideal weight Miller } & $<1.00$ & $\geq 1.00$ & $p$ value \\
\hline & $96 \%$ & $94 \%$ & 0.7077 \\
\hline \multirow[t]{2}{*}{ Weight/ideal weight Hamwi } & $<1.00$ & $\geq 1.00$ & $p$ value \\
\hline & $96 \%$ & $93 \%$ & 0.585 \\
\hline
\end{tabular}

other studies on the relationship between the results of sentinel node biopsy in breast cancer and BMI [23-25].

Currently, there are only a few available studies on qualifying patients for SLNB in CC. There weren't any satisfactory attempts to discuss qualifying patients for the procedure in regard of anthropometric features. Both a meta-analysis by Des Guetz et al. [4], a review article by Bembenek et al. [28] and the most recent meta-analysis by van der Pas et al. [31] do not raise the problem of qualification of patients in terms of anthropometric features. The issue has been addressed in a work by Cahill et al. [19] — the authors found data on BMI only in four papers included in the metaanalysis. A relationship between high BMI and intraabdominal obesity has been potentially determined as a factor that disrupts mesocolon translucency, hinders identification and increases false negative results rate in SLNB in CRC and, additionally, that causes difficulties for a surgeon. Some of the studies available for in-vivo mapping are mentioned in Table 4. They utilise simplest derivatives of height and weight, both of which are practically always measured on admittance. The question remains whether BMI is a good representation of intra-abdominal obesity which possibly may interfere with identifying marked LNs in the mesocolon.
Undoubtedly, excessive adipose tissue in the mesocolon potentially causes mistakes during the procedure, i.e. lowers detection rates or increases number of false negative results. This conclusion is, however, based on the authors' experience, not EBM data.

In the study of Thomas et al. [32], an assumption was made that thickened mesocolon containing excessive adipose tissue may impede with identifying LNs. An obligatory division of patients into groups was made in the analysis, based on calculated BMI: underweight patients, BMI< $18.5 \mathrm{~kg} / \mathrm{m}^{2}$; normal weight patients, BMI 18.5-24.9 kg/ $\mathrm{m}^{2}$; overweight patients, BMI $25-29.9 \mathrm{~kg} / \mathrm{m}^{2}$; obese patients, BMI $>30 \mathrm{~kg} / \mathrm{m}^{2}$. In the group of 61 (out of 69 included in the study), there was no statistically significant difference found in precision of LNM nor the number of false negative results comparing the group of underweight patients and those with normal weight with the group of overweight and obese patients. It was concluded that BMI alone does not inform about body fat distribution - patients with the same BMI may have different amounts of mesocolon fat.

Another study [33] analysed 31 patients with average BMI of $25.3 \mathrm{~kg} / \mathrm{m}^{2}(19.5-38.3)$. There were no statistically 


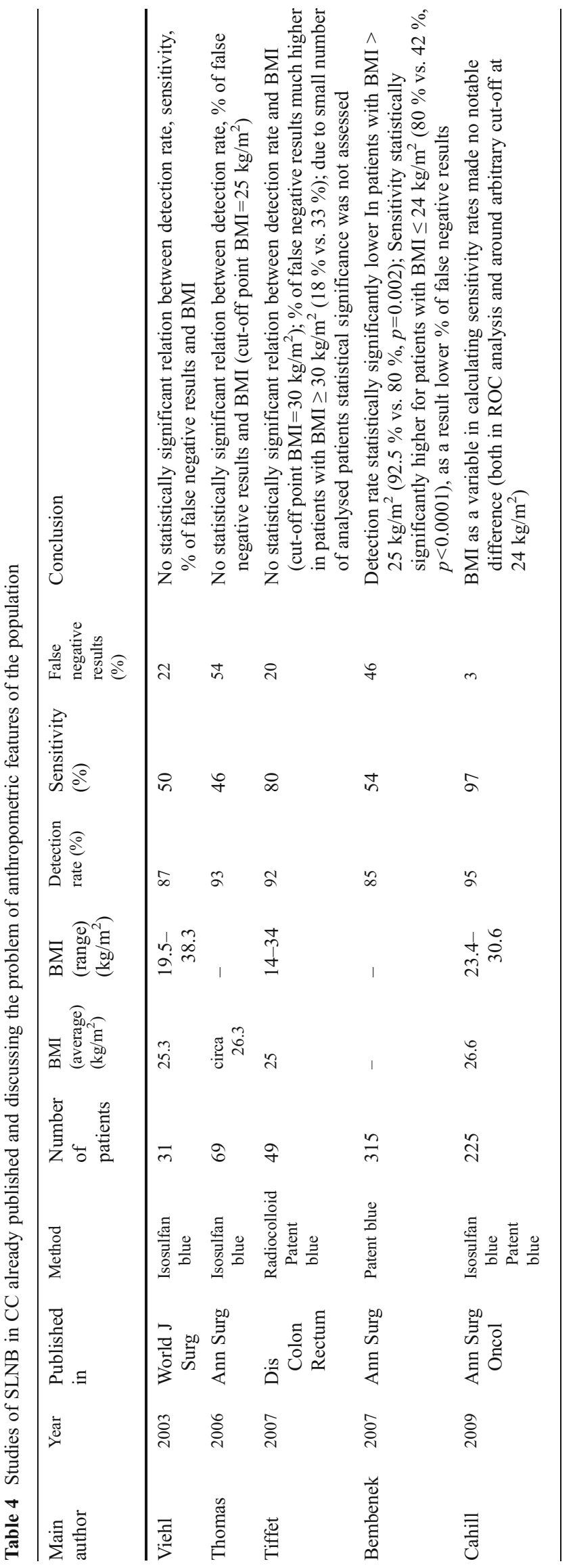

significant differences in BMI found between groups with positive and negative identification of SLN. In the study of Tiffet et al. [26], an assumption was made that obesity determined by BMI is a potential reason of detection failure. However, there was no statistically significant relation between detection rates and patients' BMI. It was determined that sensitivity was higher (53\% vs. $40 \%)$ and false negative results percentage lower (18\% vs. $33 \%$ ) in patients with $\mathrm{BMI}<30 \mathrm{~kg} / \mathrm{m}^{2}$, but no statistical significance was shown.

A study by Cahill et al. [18] that examined the available data bases from a multi-centre German study [27] and material by Saha et al. [8], analysed in detail the results of SLNB for early changes- $\mathrm{T} 1$ and $\mathrm{T} 2$. The relationship between sensitivity and BMI was analysed both with the use of ROC and the arbitrary cut-off point $-24 \mathrm{~kg} / \mathrm{m}^{2}$. No statistically significant relationship was demonstrated in any of the analyses. However, it is emphasised in the Discussion section that including BMI in the exclusion criteria, hypothetically, is one of the ways of increasing the procedure sensitivity.

Similarly to the four above-mentioned studies, our research in ROC analysis did not show any relation between BMI and SLNB in CC results. Also, in the analyses conducted for arbitrary cut-off points (BMI of 23 and 25), no statistically significant relationships were found; what may be found puzzling is that better results for sensitivity and accuracy were obtained for the patients with higher BMI.

In a multi-centre German study [27], the examined population consisted of 315 patients. It concluded that a statistically higher detection rate was achieved in a group with $\mathrm{BMI} \leq 25 \mathrm{~kg} / \mathrm{m}^{2}$ as compared to the group with $\mathrm{BMI}>25 \mathrm{~kg} / \mathrm{m}^{2}(92.5 \%$ vs. $80 \%, p=0.003)$. Additionally, it was proven for the examined population that there is a statistically significant inverse relation between BMI and sensitivity $(p=0.009)$. This relation was found in ROC graph analysis comparing groups with $\mathrm{BMI} \leq 24 \mathrm{~kg} / \mathrm{m}^{2}$ (sensitivity $80 \%$ ) and $\mathrm{BMI}>$ $24 \mathrm{~kg} / \mathrm{m}^{2}$ (sensitivity $\left.42 \%\right)(p<0.0001)$. Furthermore, it was observed that SLNB in patients with BMI $\leq 24 \mathrm{~kg} / \mathrm{m}^{2}$ conducted in centres with more experience, the sensitivity was as high as $88 \%$. The summary underlined LVs visualisation problem in obese patients and the influence of BMI on achieved SLNB results.

In summary, our research has not proved any statistically significant indicator to have high diagnostic and prognostic value. There was no statistical significance shown for BMI-value which is most frequently examined. Also, we failed to demonstrate significance of any other indicator in spite of differences in the sensitivity and accuracy of lymphatic mapping, running into $19 \%$ for some parameters. Thus, the problem of qualifying patients for SLNB in CC remains open and requires further analysis on larger populations. 
Acknowledgements The study was supported by grant KBN number NN403 384433 of the Polish Ministry of Science and Higher Education.

\section{Conflicts of interest None}

Open Access This article is distributed under the terms of the Creative Commons Attribution License which permits any use, distribution, and reproduction in any medium, provided the original author(s) and the source are credited.

\section{References}

1. Wright FC, Law CH, Berry S, Smith AJ (2009) Clinically important aspects of lymph node assessment in colon cancer. J Surg Oncol 99(4):248-255

2. Dionigi G, Castano P, Rovera F, Boni L, Annoni M, Villa F, Bianchi V, Carrafiello G, Bacuzzi A, Dionigi R (2007) The application of sentinel lymph node mapping in colon cancer. Surg Oncol 16(uppl 1):S129-S132

3. Iddings D, Bilchik A (2007) The biologic significance of micrometastatic disease and sentinel lymph node technology on colorectal cancer. J Surg Oncol 96(8):671-677

4. Des Guetz G, Uzzan B, Nicolas P, Cucherat M, de Mestier P, Morere JF, Breau JL, Perret G (2007) Is sentinel lymph node mapping in colorectal cancer a future prognostic factor? A metaanalysis. World J Surg 31(6):1304-1312

5. Bianchi PP, Ceriani C, Rottoli M, Torzilli G, Roncalli M, Spinelli A, Montorsi M (2007) Laparoscopic lymphatic mapping and sentinel lymph node detection in colon cancer: technical aspects and preliminary results. Surg Endosc 21(9):1567-1571

6. Lim SJ, Feig BW, Wang H, Hunt KK, Rodriguez-Bigas MA, Skibber JM, Ellis V, Cleary K, Chang GJ (2008) Sentinel lymph node evaluation does not improve staging accuracy in colon cancer. Ann Surg Oncol 15(1):46-51, Epub 2007 Nov 6

7. Wood TF, Nora DT, Morton DL, Turner RR, Rangel D, Hutchinson W, Bilchik AJ (2002) One hundred consecutive cases of sentinel lymph node mapping in early colorectal carcinoma: detection of missed micrometastases. J Gastrointest Sur 6(3):322-329, discussion 229-30

8. Saha S, Seghal R, Patel M et al (2006) A multicenter trial of sentinel lymph node mapping in colorectal cancer: prognostic implications for nodal staging and recurrence. Am J Surg 191:305310

9. van der Zaag ES, Buskens CJ, Kooij N, Akol H, Peters HM, Bouma WH, Bemelman WA (2009) Improving staging accuracy in colon and rectal cancer by sentinel lymph node mapping: a comparative study. Eur J Surg Oncol 35(10):1065-1070, Epub 2009 Mar 4

10. Bilchik AJ, DiNome M, Saha S, Turner RR, Wiese D, McCarter M, Hoon DS, Morton DL (2006) Prospective multicenter trial of staging adequacy in colon cancer: preliminary results. Arch Surg 141(6):527-533, discussion 533-4

11. Hirche C, Mohr Z, Kneif S, Doniga S, Murawa D, Strik M, Hünerbein M (2011) Ultrastaging of colon cancer by sentinel node biopsy using fluorescence navigation with indocyanine green. Int $\mathbf{J}$ Colorectal Dis. Sep 13. International Journal of Colorectal Disease 27(3) 319-324. doi: 10.1007/s00384-011-1306-5

12. Wiese DA, Saha S, Badin J, Ng PS, Gauthier J, Ahsan A, Yu L (2000) Pathologic evaluation of sentinel lymph nodes in colorectal carcinoma. Arch Pathol Lab Med 124(12):1759-1763
13. Quadros CA, Lopes A, Araujo I, Fregnani JH, Fahel F (2008) Upstaging benefits and accuracy of sentinel lymph node mapping in colorectal adenocarcinoma nodal staging. J Surg Oncol 98 (5):324-330

14. Andre T, Boni C, Mounedji-Boudiaf L et al (2004) Oxaliplatin, fluorouracil, and leucovorin as adjuvant treatment for colon cancer. N Engl J Med 350:2343-2351

15. Kuebler JP, Wieand HS, O'Connell MJ et al (2007) Oxaliplatin combined with weekly bolus fluorouracil and leucovorin as surgical adjuvant chemotherapy for stage II and III colon cancer: results from NSABP C-07. J Clin Oncol 25:2198-2204

16. Esser S, Reilly WT, Riley LB, Eyvazzadeh C, Arcona S (2001) The role of sentinel lymph node mapping in staging of colon and rectal cancer. Dis Colon Rectum 44(6):850-854, discussion 854-6

17. Murawa D, Nowaczyk P, Hünerbein M, Połom K, Filas V, Breborowicz J, Murawa P (2011) One hundred consecutive cases of sentinel lymph node mapping in colon cancer-the results of prospective, single-centre feasibility study with implementation of immunohistochemical staining. Int J Colorectal Dis 26(7):897-902

18. Cahill RA, Bembenek A, Sirop S, Waterhouse DF, Schneider W, Leroy J, Wiese D, Beutler T, Bilchik A, Saha S, Schlag PM (2009) Sentinel node biopsy for the individualization of surgical strategy for cure of early-stage colon cancer. Ann Surg Oncol 16(8):2170 2180

19. Cahill RA, Leroy J, Marescaux J (2008) Could lymphatic mapping and sentinel node biopsy provide oncological providence for local resectional techniques for colon cancer? A review of the literature. BMC Surg 8:17

20. Goyal A, Newcombe RG, Chhabra A, Mansel RE, ALMANAC Trialists Group (2006) Factors affecting failed localisation and false-negative rates of sentinel node biopsy in breast cancerresults of the ALMANAC validation phase. Breast Cancer Res Treat 99(2):203-208, Epub 2006 Mar 16

21. Straalman K, Kristoffersen US, Galatius H, Lanng C (2008) Factors influencing sentinel lymph node identification failure in breast cancer surgery. Breast 17(2):167-171, Epub 2007 Oct 22

22. Derossis AM, Fey JV, Cody HS 3rd, Borgen PI (2003) Obesity influences outcome of sentinel lymph node biopsy in early-stage breast cancer. J Am Coll Surg 197(6):896-901

23. Cox CE, Dupont E, Whitehead GF, Ebert MD, Nguyen K, Peltz ES, Peckham D, Cantor A, Reintgen DS (2002) Age and body mass index may increase the chance of failure in sentinel lymph node biopsy for women with breast cancer. Breast J 8(2):88-91

24. Gawlick U, Mone MC, Nelson ET, Hansen HJ, Nelson EW (2010) Success in sentinel lymph node procedures in obese patients with breast cancer. Am J Surg 200(6):707-710, discussion 710-1

25. Takei H, Suemasu K, Kurosumi M, Horii Y, Ninomiya J, Kamimura M, Naganuma R, Uchida K, Igarashi K, Inoue K, Tabei T (2006) Added value of the presence of blue nodes or hot nodes in sentinel lymph node biopsy of breast cancer. Breast Cancer 13(2):179-185

26. Tiffet $\mathrm{O}$, Kaczmarek $\mathrm{D}$, Chambonnière ML, Guillan $\mathrm{T}$, Baccot $\mathrm{S}$, Prévot N, Bageacu S, Bourgeois E, Cassagnau E, Lehur PA, Dubois F (2007) Combining radioisotopic and blue-dye technique does not improve the false-negative rate in sentinel lymph node mapping for colorectal cancer. Dis Colon Rectum 50:962-970

27. Bembenek A, Rosenberg R, Wagler E, Gretschel S, Sendler A, Siewert JR, Nährig J, Witzigmann H, Hauss J, Knorr C, Dimmler A, Gröne J, Buhr HJ, Haier J, Herbst H, Tepel J, Siphos B, Kleespies A, Koenigsrainer A, Stoecklein NH, Horstmann O, Grützmann R, Imdahl A, Svoboda D, Wittekind C, Schneider W, Wernecke KD, Schlag PM (2007) Sentinel lymph node biopsy in colon cancer: a prospective multicenter trial. Ann Surg 245:858-863

28. Bembenek A, String A, Gretschel S, Schlag PM (2008) Technique and clinical consequences of sentinel lymph node biopsy in colorectal cancer. Surg Oncol 17:183-193 
29. Bilchik AJ, Nora DT, Sobin LH, Turner RR, Trocha S, Krasne D, Morton DL (2003) Effect of lymphatic mapping on the new tumornode-metastasis classification for colorectal cancer. J Clin Oncol 21:668-672

30. Aikou T, Kitagawa Y, Kitajima M, Uenosono Y, Bilchik AJ, Martinez SR, Saha S (2006) Sentinel lymph node mapping with GI cancer. Cancer Metastasis Rev 25:269-277

31. van der Pas MH, Meijer S, Hoekstra OS, Riphagen II, de Vet HC, Knol DL, van Grieken NC, Meijerink WJ (2011) Sentinel-lymph- node procedure in colon and rectal cancer: a systematic review and meta-analysis. Lancet Oncol 12(6):540-550, Epub 2011 May 4

32. Thomas KA, Lechner J, Shen P, Waters GS, Geisinger KR, Levine EA (2006) Use of sentinel node mapping for cancer of the colon: 'to map or not to map". Am Surg 72:606-611

33. Viehl CT, Hamel CT, Marti WR, Guller U, Eisner L, Stammberger U, Terracciano L, Spichtin HP, Harder F, Zuber M (2003) Identification of sentinel lymph nodes in colon cancer depends on the amount of dye injected relative to tumor size. World J Surg 27:1285-1290 